\title{
Metodologias Ativas na Educação: uso de aplicativos Google na realização de projetos colaborativos
}

\author{
Vinicius Carvalho de Aragão Santana ${ }^{1}$, Rachel de Sousa Ferreira ${ }^{1}$ \\ ${ }^{1}$ Colégio Andrews - Rio de Janeiro - RJ - Brasil \\ vinicius.carvalho.aragao@gmail, rachelferreirabr@gmail.com, \\ \{vinicius, rachelferreira\} dandrews.g12.br
}

\begin{abstract}
This article reports on the experience of students in the third year of elementary school, at a private school, during social studies class. The collaborative activity built by the students, was focused on the study of the city of Rio de Janeiro, as well as the social problematization and possible solutions. The use of Google applications allowed the creation of an integrated project, which developed autonomy, creativity and group work.
\end{abstract}

Resumo. Este artigo relata a experiência vivenciada por alunos do terceiro ano do Ensino Fundamental de uma escola privada durante as aulas de Estudos Sociais. A atividade colaborativa construida pelos estudantes teve como objetivo o estudo da cidade do Rio de Janeiro, assim como a problematização social e o levantamento de soluções. A utilização dos aplicativos Google permitiram a criação de um projeto integrado, que desenvolveu autonomia, criatividade e trabalho em grupo.

\section{Introdução}

As tecnologias digitais aplicadas à sala de aula vêm revolucionando a aprendizagem. Elas propiciam a criação de novas metodologias através de práticas que envolvem a colaboração e a criatividade, incentivando a autonomia e a confiança.

Novas formas de aprender e ensinar levam os educadores a refletir sobre as possibilidades de integração das tecnologias digitais ao ensino. Atividades como: projetos grupais e individuais, desafios e jogos, fazem parte das Metodologias Ativas, que são "pontos de partida para avançar para processos mais avançados de reflexão, de integração cognitiva, de generalização, de reelaboração de novas práticas” (MORAN, 2015, p.18), colocando o aluno como principal agente da sua aprendizagem.

Sendo assim, este artigo tem como objetivo relatar a experiência vivenciada pelos alunos do $3^{\circ}$ ano do Ensino Fundamental de uma escola privada, do Rio de Janeiro, durante as aulas de Estudos Sociais. Eles foram convidados a conhecer a cidade onde vivem, levantar questões sociais, físicas e culturais, discuti-las e buscar soluções para os problemas abordados.

Os softwares do Google foram inseridos à atividade para promover o trabalho colaborativo. Através dos diversos aplicativos que a plataforma disponibiliza gratuitamente, os estudantes puderam construir um projeto com momentos de estudo e lazer, tanto no ambiente escolar, quanto em casa.

Discutiremos também a importância do trabalho em grupo, e da utilização de recursos digitais de cooperação na nuvem para desenvolver projetos educacionais, assim como suas implicações pedagógicas. Este artigo foi inspirado em trabalhos de autores como Lima, Nascimento, Neto e Filho (2016) que tiveram como propósito realizar uma atividade integrada através de aplicativos Google. 
VII Congresso Brasileiro de Informática na Educação (CBIE 2018)

Anais dos Workshops do VII Congresso Brasileiro de Informática na Educação (WCBIE 2018)

\section{Métodos}

Nas aulas de Estudos Sociais, os estudantes do $3^{\circ}$ ano foram desafiados a conhecer mais sobre o "Rio de Janeiro". Discutir sobre o local onde vivem é importante, pois situa os alunos e os fazem entender o espaço que ocupam no Brasil e no mundo.

No decorrer das aulas, foram realizadas diversas pesquisas acerca do assunto, entretanto, o que era apenas uma atividade sobre os aspectos físicos, tornou-se um debate a respeito dos problemas que a cidade vive atualmente. Muitas questões foram sendo apresentadas e a ida ao laboratório de mídias impulsionou, tanto os estudantes quanto os professores, para a realização de um projeto colaborativo. Segundo Moran:

Na educação, acontecem vários tipos de mistura, blended ou educação híbrida: de saberes e valores, quando integramos várias áreas de conhecimento (no modelo disciplinar ou não); de metodologias, com desafios, atividades, projetos, games, grupais e individuais, colaborativos e personalizados. Também falamos de tecnologias híbridas, que integram as atividades da sala de aula com as digitais, as presenciais com as virtuais. Híbrido também pode ser um currículo mais flexível, que planeje o que é básico e fundamental para todos e que permita, ao mesmo tempo, caminhos personalizados para atender às necessidades de cada aluno. Híbrido também é a articulação de processos de ensino e aprendizagem mais formais com aqueles informais, de educação aberta e em rede. Implica misturar e integrar áreas, profissionais e alunos diferentes, em espaços e tempos distintos. (MORAN, 2017, p. 28 e 29$)$

A turma levantou alguns assuntos pertinentes como: geografia, pontos turísticos, educação, saúde, lazer, cultura e segurança. A turma foi dividida em sete grupos de quatro alunos e cada grupo ficou responsável por pesquisar os assuntos destacados no laboratório de médias, para posteriormente debaterem em sala.

Para instigar ainda mais os estudantes, utilizamos a Realidade Virtual para levá-los a uma experiência de imersão a alguns locais da cidade. Para isso, foram usados dois celulares, com o aplicativo Google Expeditons instalados, e dois óculos de papelão do Google Cardboard. A atividade acarretou em uma onda de entusiasmo. Eles nunca haviam vivenciado este tipo de experiência, todavia, por termos apenas dois equipamentos disponíveis, tivemos que fazer um rodízio dos óculos, o que ocasionou em alguns conflitos, que tiveram que ser mediados.

Os programas Google Earth e Google Maps foram disponibilizados para que os alunos pudessem explorar a cidade do Rio de Janeiro e entender aspectos geográficos como: áreas florestais, planaltos, planícies e montanhas. Para identificar as áreas urbanas, utilizamos o aplicativo Google Street View, e eles puderam observar: ruas, cruzamentos, avenidas, comunidades e estabelecimentos, reconhecendo, assim, os espaços onde vivem.

O aplicativo online Google My Maps (diferente do Google Maps, que possui aplicabilidade apenas para consulta) permite que os alunos insiram suas próprias informações e experiências, possibilitando a construção de um "mapa colaborativo". Sendo assim, foi a maneira escolhida para concretizar todo o estudo que estava sendo realizado. Ele estimula a personalização, a pesquisa, o compartilhamento, a colaboração e a criatividade. De acordo com Lima, Nascimento, Neto e Filho:

"A aprendizagem acontece através da interação entre alunos, os quais levantam perguntas, realizam investigações e ensinam uns aos outros tanto de forma presencial quanto usando ambientes computacionais. (...) algumas das vantagens disponibilizadas pela tecnologia para auxiliar a aprendizagem colaborativa são: a facilidade com que a tecnologia de informação e comunicação permite criar, mover, compartilhar informações na forma de textos, imagens e vídeos, e a capacidade de interagir e de produzir colaborativamente, 
VII Congresso Brasileiro de Informática na Educação (CBIE 2018)

Anais dos Workshops do VII Congresso Brasileiro de Informática na Educação (WCBIE 2018)

fornecendo novas formas de aprendizagem. " (LIMA, NASCIMENTO, NETO E FILHO, 2016, p. 388)

Cada grupo contribuiu para a confecção do mapa inserindo materiais criados por eles próprios, como: vídeos, fotos tiradas na hora ou pesquisadas e textos escritos e problematizados em sala. Não apenas foram retratadas as questões físicas, mas também os problemas sociais, como: poluição, violência, falta de infraestrutura, preconceito e acessibilidade. Estas questões foram discutidas, apontadas e os estudantes propuseram possíveis soluções.

Para a finalização do trabalho, foi escolhida a plataforma Google Sites para expor o mapa criado em conjunto pela turma. Os alunos puderam estudar todo o conteúdo elaborado por eles e pelos demais colegas, de forma integrada.

No momento, o site e o mapa continuam sendo alimentados semanalmente para que, no final do ano, o projeto possa ser apresentado para os pais e para a comunidade escolar.

\section{Resultados, discussão e conclusão}

Segundo o relato da professora do terceiro ano, a realização do projeto propiciou uma melhora significativa na participação dos alunos, que durante as aulas demonstraram interesse em debater os assuntos. Eles estudaram não apenas a cidade do Rio de Janeiro sob o ponto de vista geográfico, como era esperado no início, mas também questões sociais que foram aprofundadas.

Ao iniciar a conversa sobre a cidade, muitos estudantes relataram as notícias que viam na televisão e na internet. Embora não soubessem os conceitos, eles se sentiam incomodados com os problemas sociais. A professora sistematizou as questões trazidas por eles, dividindo em temas a serem trabalhados.

A autonomia na busca de informações também foi um ponto central. Buscar sites confiáveis, checar os dados e colocar referências foi essencial para que desenvolvessem independência em buscar informações na rede, compara-las e critica-las.

A utilização dos recursos tecnológicos de aprendizagem do Google favoreceu a fluidez do projeto, pois os aplicativos permitem o compartilhamento de informações, a criação de documentos colaborativos e a personalização do mapa. O uso da Realidade Virtual, através do software Google Expeditions, estimulou a ludicidade e a criatividade, e possibilitou a imersão em novos espaços.

O trabalho em grupo foi uma decisão proposital. Cada quarteto dividia um computador, o que permitiu discussões a respeito do projeto e sobre a seleção de quais informações e mídias seriam inseridas. Foi observado que a relação ensino-aprendizagem também ocorreu entre os próprios alunos que, ao trabalharem juntos, mostravam para os colegas as novas descobertas. Segundo Sunaga e Carvalho:

"Os estudantes podem se sentir mais estimulados ao perceber sua progressão constante e sua autonomia sendo alcançada a cada atividade. Eles podem ser desafiados a encontrar soluções para os mais diversos problemas, a trabalhar em grupo, respeitando a individualidade e a capacidade dos seus colegas, o que os preparará para viver em um mundo mais dinâmico e complexo." (SUNAGA E CARVALHO, 2017, p. 142)

Durante a construção do mapa colaborativo houve necessidade dos professores mediarem conflitos ocasionados pelo desaparecimento de informações. Como se tratava de um arquivo que poderia ser editado por qualquer pessoa com acesso, era difícil detectar quem havia apagado. Somente através de conversas, explicando a responsabilidade de se trabalhar em conjunto, respeitando os demais colegas, conseguimos extinguir esse problema e a turma 
VII Congresso Brasileiro de Informática na Educação (CBIE 2018)

Anais dos Workshops do VII Congresso Brasileiro de Informática na Educação (WCBIE 2018)

intensificou o seu entendimento de coletivo. Segundo o documento da Base Nacional Comum Curricular (BNCC):

"Compreender, utilizar e criar tecnologias digitais de informação e comunicação de forma crítica, significativa, reflexiva e ética nas diversas práticas sociais (incluindo as escolares) para se comunicar, acessar e disseminar informações, produzir conhecimentos, resolver problemas e exercer protagonismo e autoria na vida pessoal e coletiva" (BNCC, 2017, p.9)

Desenvolver atividades que estimulam a criatividade e o trabalho colaborativo faz com que a aprendizagem se torne significativa, assim, o conhecimento é construído por cada indivíduo de maneira personalizada. Reinventar a sala de aula é um desafio que faz parte do novo papel do professor, que mais do que mediar, deve incentivar e ser agente encorajador, para abrir os horizontes dos seus alunos.

\section{Referências}

BRASIL. Ministério da Educação. Secretaria da Educação Básica. Base nacional comum curricular. Brasília, DF, 2016. Disponível em: <http://basenacionalcomum.mec.gov.br/wpcontent/uploads/2018/04/BNCC_19mar2018_versaofinal.pdf>. Acesso em 15 de maio de 2018.

Lima, M., Nascimento, K., Neto, C., Filho, J., Aplicativo de Desenho do Google Drive: uma análise com foco na aprendizagem colaborativa com suporte computacional. Anais do XXII Workshop de Informática na Escola (WIE 2016). Disponível em: <http://www.brie.org/pub/index.php/wie/article/view/6845> Acesso em 10 de maio de 2018.

Moran, J., As tecnologias digitais no ensino híbrido. In: Bacich, L., Neto, A., Trevisani, F. Ensino Híbrido: Personalização e tecnologia na educação. Edição: 2. Local de publicação: Porto Alegre. Editora: Penso. 2015.

Moran, J., Mudando a educação com metodologias ativas. Coleção Mídias Contemporâneas. Convergências Midiáticas, Educação e Cidadania: aproximações jovens. Vol. II]Carlos Alberto de Souza e Ofelia Elisa Torres Morales (orgs.). PG: Foca Foto-PROEX/UEPG, 2015. Disponível em : $\quad<$ http://www2.eca.usp.br/moran/wpcontent/uploads/2013/12/mudando_moran.pdf $>$ Acesso em 08 de março de 2018.

Sunaga, A., Carvalho, C., As tecnologias digitais no ensino híbrido. In: Bacich, L., Neto, A., Trevisani, F. Ensino Híbrido: Personalização e tecnologia na educação. Edição: 2. Local de publicação: Porto Alegre. Editora: Penso. 2015. 